\title{
TURISMO E A EMERGÊNCIA DE NOVAS TERRITORIALIDADES: O CASO DE ITAÚNAS-ES
}

\author{
Julia Salvador Martins ${ }^{1}$ \\ Silvia Maria Guerra Molina ${ }^{2}$
}

\section{Introdução}

O turismo é uma atividade econômica que, ao ser desenvolvido sem planejamento adequado, pode ocasionar mudanças no território dos lugares onde se insere. Interfere tanto no ambiente natural, quanto cultural da população receptora e tem um papel na produção e consumo do espaço.

Muitas vezes o turismo, da maneira como vem se consolidando em vários lugares do Brasil, acarreta transformações na vida das comunidades receptoras. Caracterizam-se alguns conflitos sócio-ambientais devido à questão da posse e uso da terra, a mudanças no padrão de comportamento e impactos no ambiente. Por esses motivos, o turismo freqüentemente se constitui, na abordagem da Ecologia Humana, num agente estressor atuante na desorganização das relações ecológicas, sociais, econômicas e culturais da população receptora. Como agente estressor, o turismo pode vir a desestruturar o modo de vida de populações nativas causando uma fragmentação do território e eventualmente, contribuindo para a emergência de territorialidades inéditas.

Itaúnas, distrito rural do município de Conceição da Barra-ES, apresenta um ambiente atrativo para o turismo. Isso se deve à conjugação de características naturais, representadas pelas dunas e mar e pelo contraste das mesmas com as áreas de alagados. Suas praias e características culturais também se constituem em atrativos, destacando-se os sítios e monumentos históricos, as manifestações folclóricas, artesanais e culturais. Nesse distrito, o turismo no local teve sua ascensão a partir da década de 90. Desse processo decorrem novas territorialidades.

\footnotetext{
${ }^{1}$ Professora do Instituto Superior de Educação - Uniararas, mestre pelo Programa de Pós-Graduação Interunidades em Ecologia de Agroecossistemas (PPGI-EA), na Escola Superior de Agricultura Luiz de Queiroz - USP. E-mail: julia@ uniararas.br

2 Professora Doutora do Departamento de Genética, da Escola Superior de Agricultura Luiz de Queiroz, Universidade de São Paulo. E-mail: smgmolin@esalq.usp.br
} 
Nesse sentido, sob os referenciais teóricos da Ecologia Humana e interfaces com outras áreas do conhecimento como a Geografia e Antropologia, este trabalho busca entender as relações complexas que os moradores de Itaúnas estabelecem com seus territórios de vida, a partir das influências exercidas principalmente pelo turismo, adotando-se como eixo central da presente análise, o conceito de territorialidade.

Ultimamente bastante difundido, principalmente na ciência geográfica, o conceito de territorialidade contribui para um debate mais amplo, no que se refere às novas e cada vez mais complexas problemáticas relacionadas às formas com que a sociedade humana se relaciona, modela e organiza o espaço no qual vive e se reproduz.

No presente trabalho o conceito de territorialidade será empregado procurando respeitar suas várias dimensões. Assim, este conceito será compreendido tanto do ponto de vista das ciências naturais, como também do ponto de vista das ciências humanas.

A discussão do conceito de territorialidade se inicia com o entendimento do conceito de território. Segundo (Raffestin, 1993) este é entendido como um espaço onde se realizou um trabalho na forma de energia ou de informação, o qual, sua vez, manifesta relações de poder. Assim, ao se apropriar de um espaço, concreta ou abstratamente, o ator territorializa o espaço.

Já para (Santos, 2002) o território também pode ser entendido como o território de uso, não o território em si. O território é o chão somado à identidade. A identidade é o sentimento de pertencer àquilo que nos pertence. Então, o território é o fundamento do trabalho, o lugar da residência, das trocas materiais e espirituais, do exercício da vida.

Espaço concreto em que se produzem ou se fixam os processos sociais, o território, visto dentro de uma dimensão do imaginário, pode ser considerado fruto de uma apropriação simbólica, especialmente através das identidades territoriais, ou seja, da identificação que determinados grupos sociais desenvolvem para com seus espaços vividos e o significado que dão a eles (HAESBAERT, 2002).

Para (Faria, 2001) a concepção de território está igualmente ligada à idéia de domínio ou gestão de uma determinada área. Esta área recebe uma função, dependendo da forma de apropriação. A apropriação pode se dar tanto por grupos sociais, pelo poder público estatal e(ou) pelo poder das grandes empresas capitalistas que lançam seus tentáculos sobre grandes áreas territoriais. Neste contexto, o território assume um duplo sentido, seja pelo controle de fato efetivo legitimado pelo poder, ou por outro lado, vinculando-se à dimensão afetiva e associando-se à identidade de grupos sociais e à afetividade espacial. 
As idéias de ligação afetiva e também da defesa do território pelos seres humanos nos fazem ampliar esta discussão e acrescentar outro elemento, a territorialidade, procurando respeitar suas várias dimensões. Assim, também a territorialidade é entendida tanto do ponto de vista biológico, como do ponto de vista das ciências humanas.

$\mathrm{O}$ estudo da territorialidade tem como ponto de partida uma abordagem que considera a conduta territorial como parte integral de todos os grupos humanos, um comportamento humano espacial que existe e possui uma expressão de poder. Nesse contexto, a territorialidade é considerada como o esforço coletivo de um grupo social para ocupar, usar, controlar, afetar e se identificar com uma parcela específica de seu ambiente biofísico, convertendo-a assim em seu território (LITTLE, 2004; SANTOS, 2002).

Para (Andrade, 2002) a territorialidade é vista como "um processo subjetivo de conscientização da população de fazer parte de um território. Ou seja, a ligação ou a interrelação entre ambos, sendo o conjunto das práticas e suas expressões materiais, capazes de garantir a apropriação e permanência de um dado território por um determinado agente social, tendo muitas características com o espaço vivido, marcado por trocas de experiências entre o território e o indivíduo por serem ambos dinâmicos, interagindo reciprocamente".

Dentro de uma dimensão cultural, a territorialidade pode ser definida como a construção do espaço, a dotação de sentido ao lugar que se habita, ao qual se pertence, por meio de práticas cotidianas. Essas práticas referem-se aos modos pelo qual um determinado grupo social consegue manter e reproduzir sua cultura. Além disso, a territorialidade é o sentimento que emana da consciência de pertencer a um território (CHAVEZ, 2003).

Outra visão importante do conceito de territorialidade está apoiada na vertente das ciências naturais. Neste contexto, o conceito de territorialidade está relacionado com a conduta característica adotada por um organismo para tomar posse de um território e defendêlo contra os membros de sua própria espécie.

Assumindo-se que a territorialidade também está ligada à idéia de riqueza e distribuição espacial dos recursos mais vitais dentro da área de domínio e ao processo pelo qual um ou mais indivíduos delimitam certa área e a defendem de invasão por outros indivíduos da mesma espécie, ela poderá estar ligada à defesa do território. Da mesma forma, poderá estar associada às estratégias de uso e exploração dos espaços coletivos e individuais, dos quais vão ser extraídos os recursos naturais para subsistência e os materiais necessários para o desenvolvimento da tecnologia característica desta sociedade. (IGNARRA, 2000). 
Cabe ressaltar, entretanto, que cada cultura desenvolve suas próprias regras particulares para salvaguardar a propriedade e o espaço individual. Na espécie humana há um maior controle conservacionista sobre o ambiente quando há uma demarcação territorial definida sobre uma região (IGNARRA, 2000).

Em síntese, as populações humanas podem manter relações estreitas com o território, sendo isto expresso por meio da territorialidade, ou seja, através do sentimento de pertencer ao território vivido, da sua defesa e de outras manifestações biológicas e culturais associadas ao território e à territorialidade.

\section{Metodologia}

\section{Caracterização geográfica e histórica de Itaúnas:}

A Vila de Itaúnas faz parte do município de Conceição da Barra, ES. Localiza-se na porção norte do Estado do Espírito Santo, região Sudeste do Brasil. Distante $256 \mathrm{~km}$ de Vitória, capital do Estado, Itaúnas encontra-se entre os limites do Parque Estadual de Itaúnas (PEI) e talhões de eucalipto plantados em larga escala.

A área do PEI está inserida dentro do bioma de Mata Atlântica e exibe ecossistemas como Mata de Tabuleiro, Restinga, Manguezal, Rios, Alagado, Dunas e Praia.

Inserido no Corredor Ecológico da Mata Atlântica, o PEI, interliga importantes fragmentos florestais do Espírito Santo e Bahia, aumentando a conexão entre eles, contribuindo assim para a conservação da diversidade biológica.

A história de Itaúnas remete a um processo de soterramento da antiga Vila iniciado na década de 50. Já na década de 70, toda a antiga organização espacial da população desapareceu totalmente, cedendo lugar às dunas móveis. Os moradores então, se viram forçados a se mudar para o outro lado da margem do rio e a construir neste local uma nova Vila (PETROFF, 2003).

As dunas encobriram a antiga Vila e hoje nesse local, encontram-se sítios arqueológicos pertencentes à atual área do Parque Estadual de Itaúnas. Estudos arqueológicos realizados por Perota citado em (Ferreira, 2002), afirmam que a história da ocupação humana em Itaúnas remete a quatro períodos distintos. Estes seriam $(a)$ o dos caçadores e coletores de molusco que utilizavam a pedra lascada e polida; $(b)$ o período da agricultura, da pesca e da cerâmica; (c) o período de contato dos primeiros europeus com a população indígena e $(d)$ a fundação da Vila de Itaúnas e o período de desenvolvimento desta. 
Em ambiente de alta diversidade de recursos, até meados do século $\mathrm{XX}$, a população local desenvolvia um modo de vida considerado tradicional, baseado no uso comunal e extrativista do território e dos recursos naturais. A população humana manejava os recursos do ambiente natural e supria grande parte das necessidades de subsistência, obtendo em seu território, água, peixes, carnes, frutos, madeira, cipó, raízes e ervas medicinais (FERREIRA, 2002).

A região de Itaúnas, onde hoje se localizam as cidades de São Mateus e Conceição da Barra, era conhecida como a região do Sapê do Norte, sendo habitada historicamente por negros africanos. Durante o regime de escravidão, os fugitivos iam para essa região. Os escravos acabaram formando núcleos de resistência sendo estes considerados pelas autoridades locais, verdadeiros quilombos. A memória desse passado está expressa em narrativas ou nas formas de cantos e rituais de manifestação, como nas brincadeiras do Ticumbi, no Jongo, entre outras realizadas em Itaúnas até os dias atuais.

\section{Abordagem da pesquisa: qualitativa}

Devido ao universo complexo desta pesquisa, optamos pela abordagem qualitativa com a finalidade de examinar aspectos mais profundos e subjetivos do tema em estudo. Além disso, a abordagem qualitativa propiciou criar um relacionamento mais longo e flexível entre o pesquisador e os indivíduos envolvidos na pesquisa, lidando com informações intrínsecas, amplas e com maior riqueza de detalhes. Para a coleta de dados foram utilizadas técnicas Antropologia e da Ecologia Humana, utilizando a perspectiva êmica, para observar e interpretar os fenômenos e comportamentos da população humana estudada (POSEY, 1986). Desse modo, o trabalho foi realizado com os moradores de Itaúnas, numa relação onde eles foram vistos como colaboradores na coleta dos dados necessários para a pesquisa, sendo a experiência vivida por eles em seu ambiente, uma das principais fontes desta pesquisa.

Dessa forma, procurou-se compreender o fenômeno estudado a partir dos dados coletados em campo, das referências fornecidas pela população estudada em seu mundo vivido e dos significados atribuídos aos fenômenos pela população local.

Dentre as técnicas utilizadas para a coleta de dados necessários, foi utilizada a observação participante, sendo esta direcionada de acordo com os objetivos propostos pela pesquisa. Através de um roteiro, procurou-se registrar as observações feitas em várias situações, contemplando assim elementos significativos da dinâmica dos indivíduos 
envolvidos na pesquisa, no que se refere aos aspectos ecológicos, socioculturais e econômicos.

Outra técnica utilizada foi a entrevista. Procurou-se ao invés da aleatoriedade, escolher informantes intencionalmente, considerando uma série de condições. Nesse sentido, para a realização das entrevistas foram selecionados em primeiro lugar, os moradores mais idosos de Itaúnas. Foram realizados também um segundo conjunto de entrevistas com outros moradores, mais jovens e também com os mais idosos, indicados pelos primeiros, como conhecedores da história local. Essas entrevistas tiveram por objetivo apreender elementos significativos sobre o turismo e as novas territorialidades. As entrevistas se dividiram em semi-estruturadas e formais, em que foi utilizado um gravador para registrar os depoimentos e em entrevistas informais, onde foram anotados os principais aspectos na caderneta de campo. O total de entrevistados foi de 33. Destas, 10 foram gravadas e 23 foram divididas em entrevistas formais e informais, ambas sem gravador.

As entrevistas que foram registradas com gravador foram transcritas. Posteriormente procurou-se, juntamente com o conteúdo de todas as outras entrevistas que não foram gravadas, identificar os temas relevantes, assim como as idéias que continham contradições, visando estabelecer categorias para análise, de acordo com os objetivos propostos pela pesquisa. O mesmo procedimento foi adotado para a leitura e análise da caderneta de campo. Tal procedimento foi adotado, pois as respostas fornecidas tendem a serem muito variadas. Assim, para que se possa analisá-las adequadamente, de acordo com (Gil, 1999), é preciso organizá-las, o que é feito mediante o seu agrupamento em certo número de categorias.

\section{Resultados}

De acordo com as narrativas dos moradores locais, com o cenário paisagístico (dunas) sendo propagado de forma pouco intensa pela mídia, os primeiros fluxos de turistas atraídos por Itaúnas datam da década de 70, porém ainda em quantidade bastante reduzida. Na década seguinte, anos 80, o fluxo de turista começa a aumentar, sendo o local procurado principalmente por pesquisadores, jovens universitários e aventureiros. Ainda nesse período, além do baixo fluxo, as interferências no ambiente de Itaúnas foram pouco notadas.

No final da década de 80, existiam na pequena Vila, 156 residências de uso permanente e 87 residências sazonais. Nessa época, o baixo fluxo de turistas era também evidenciado pelo número de pousadas existentes, 5, e por somente 20 outros estabelecimentos comerciais 
diversos, segundo consta no plano de ordenamento da Vila de Itaúnas-ES, realizado pelo governo do Estado do Espírito Santo.

No final da década de 90 e nos três primeiros anos do século XXI, o fluxo turístico aumentou vertiginosamente. Tal aumento acelerado do turismo se deveu à elevada divulgação do local nos meio de telecomunicação e também à coexistência de diferentes tipos de turismo como o turismo de aventura.

Constatou-se o turismo de massa e o turismo da juventude, este último caracterizado por (Giaretta, 2002) como a modalidade de turismo realizada por pessoas jovens que procuram a Vila em busca do forró, que passou a ser um importante atrativo local, principalmente no mês de julho, quando acontecem o Festival Nacional de Forró e o Circuito de Forró.

No decorrer dos anos, a exploração do turismo em Itaúnas passou a ser mercantil. Desenvolvendo-se sem a criação de mecanismos de controle, ou seja, sem um planejamento adequado para esse tipo de atividade, fato que acarretou modificações desordenadas na organização e configuração espacial da Vila e interferências no modo de vida da população local.

Segundo dados da organização não governamental Sociedade Amigos do Parque de Itaúnas (SAPI), no verão de 97/98, o número de turistas chegou a 20.815 e no verão seguinte 98/99, esse número aumentou para 52.031 visitantes.

Junto com os turistas, vieram também os investidores de vários locais do Brasil, trazendo para Itaúnas investimentos de pequeno e médio porte, incrementando o comércio local com a construção de pousadas, restaurantes e bares. Os moradores locais influenciados e iludidos com a valorização imobiliária passaram a vender suas casas, sendo muitas destas transformadas em pousadas. Dessa forma, alto índice de coabitação é percebido na Vila, ou seja, mais de uma família habitando uma mesma casa.

No bojo do processo de modificação da configuração espacial, observou-se alterações em Itaúnas quanto ao uso do solo no perímetro urbano, o que provocou uma descaracterização das antigas construções, alterando o aspecto bucólico da Vila de pescadores e acentuando ainda mais o processo de estratificação do território. A parte central da Vila se tornou mais valorizada pela especulação imobiliária, transformando muitas residências locais em pousadas, restaurantes e lojas e afastando os moradores para áreas mais retiradas.

$\mathrm{Na}$ concepção de muitos moradores, o aumento do número de estabelecimentos comerciais introduzidos em seu território, por pessoas de fora, que não são nativos, trouxe 
mudanças para a economia local, excluindo-os da apropriação da renda gerada pela atividade turística. Esse fato pode ser evidenciado no relato abaixo, de uma moradora, o qual apresenta também outros elementos que confirmam a forte especulação imobiliária em Itaúnas:

"As pousadas, realmente estão acabando com os nativos, realmente quem têm pousadas aqui, não é daqui. Tem nativo que tem seu imóvel, precisa do dinheiro, ele tá passando por uma situação difícil, ele desfaz daquilo, quer dizer, o próprio nativo não tem dinheiro para comprar, mas quem vem de fora tem dinheiro. Compra ali, é uma casa, mete o pau, quebra. Daqui dois, três, quatro meses você vai lá, já tá aquela pousadona dentro. Então, os ganho são do próprio povo de fora. Então, quer dizer, vem naquele período dos três meses de verão ou dois meses, vem naquele período trabalhou ali quando juntou o dinheiro, lugar deles, quer dizer, isso faz falta para o nosso lugar. Ganha o dinheiro aqui e não gasta o dinheiro aqui. O homem da daquele ponto comercial, ele é de fora, ele veio, comprou aquele terreno ali, dois lotes era. Aí comprou os dois lotes por 60.000 reais, quer dizer, agora ele fez a pizzaria do lado de cá e partiu o lote no meio e vendeu um lote e ficou com um lote e sabe o valor que ele vendeu? Por 60.000. Agora ele nem mora mais aqui, mora em outra cidade, só vem num feriadinho deste. Trabalhou vai embora" (moradora nativa, 31 anos).

Ainda que consideremos as mudanças negativas ocorridas na estrutura da Vila de Itaúnas, em virtude do incremento do turismo, cabe ressaltar, que esse tipo de atividade trouxe geração de renda e ocupações temporárias para a população local, seja na oferta de mão-deobra, nas atividades ligadas diretamente ao turismo como pousadas, bares, restaurantes, artesanato e outros, seja na construção civil. Ressalta-se que esse fenômeno foi mais acentuado nos anos em que esta atividade se desenvolvia em maior escala, ou seja, entre os anos 1998 e 2002.

Embora haja elementos nos discursos dos moradores que indiquem a crise do turismo em Itaúnas, a renda gerada por esta atividade, principalmente nos anos de maior pico, ocorridos no final da década de 90, somada aos benefícios concedidos a muitos pescadores na época de defeso, levou de certa forma ao aumento do poder aquisitivo. Esse fato propiciou melhoras nas condições de moradia. As casas de muitos moradores foram sendo modificadas e até certo ponto tornaram-se mais confortáveis para atender aos turistas. Percebe-se também 
na maioria das residências, a introdução de produtos eletrodomésticos como fogão, geladeira, televisão e telefone.

Outro ponto a ser discutido refere-se às interferências do turismo no modo de vida da população receptora. Assim, percebe-se que este tipo de atividade gerou um processo de aculturação, ou seja, novos valores culturais foram introduzidos na vila pela presença dos turistas, e assimilados pelos moradores, principalmente pelos mais jovens.

O fato descrito acima, é preocupante, uma vez que induz o jovem ao distanciamento das práticas tradicionais que vêm caracterizando as atividades associadas à subsistência material na vila de Itaúnas, como a pesca artesanal, a produção de beiju etc. Na temporada de verão, período em que o turismo é mais desenvolvido, observa-se desde a intensificação do turismo, aumento da criminalidade, com ocorrências de furtos na Vila.

Em suma, com o incremento do turismo, notam-se as seguintes modificações em Itaúnas: valorização imobiliária, substituição do uso do solo de residencial por comercial, pressão sobre o sítio urbano da Vila que se expande em direção à rodovia ES-10, que liga Itaúnas à sede municipal Conceição da Barra, aumento do número de famílias locais sem moradia.

Além dos fatores citados acima, também foi possível observar o adensamento urbano, aumento da demanda do abastecimento de água e saneamento, excesso de veículos no período de verão, visitação massiva aos micro-ambientes frágeis do Parque Estadual de Itaúnas, excesso de resíduos sólidos gerados pelos turistas e excesso com relação à capacidade de suporte, isto é, não respeito ao número máximo de visitantes por período de tempo que uma determinada área pode suportar, sem que ocorram alterações nos meios natural e cultural.

Uma questão importante evidenciada em campo, refere-se às especulações sobre a possível pavimentação da estrada de terra que liga o distrito de Itaúnas a Conceição da Barra. $\mathrm{Na}$ visão dos moradores, as opiniões divergem com relação à benfeitoria que a estrada trará para a Vila e para o turismo, havendo tanto opiniões favoráveis como desfavoráveis.

Mesmo diante de todas as interferências geradas pelo turismo, este atualmente constitui um dos importantes elementos que compõem o panorama das relações econômicas e sociais do local. Na visão dos moradores nativos, o turismo como atividade econômica, é capaz de facilitar a entrada de dinheiro na micro-economia local, gerando renda e empregos para a população residente, são as contradições existentes. 
Cabe ressaltar ainda a nova percepção do tempo sazonal, desenvolvida pelos moradores de Itaúnas, após o advento do turismo de massa. Atualmente há o tempo da pesca (artesanal) e o tempo do turismo, respectivamente descritos pelos moradores locais como o inverno e o verão.

Com o fim da temporada do turismo, começa o "inverno" e os moradores voltam às suas outras atividades, relacionadas às suas práticas tradicionais de subsistência. Dessa forma, passam a pescar com mais intensidade no rio, as mulheres voltam ao rio quase que diariamente, para lavar roupa, limpar os peixes, fabricar farinha. As crianças voltam a brincar nas ruas da Vila, cenas que não são vistas quando os turistas estão no local. Observam-se então em Itaúnas, duas temporadas, criados pelo desenvolvimento do turismo: o tempo do viver associado às práticas tradicionais, mais próximas do ambiente natural e o tempo marcado por atividades mercantis.

Em Itaúnas, fazendo uma analogia as idéias de (Carlos, 1999), em período fora da temporada do turismo, a imagem do pescador(a), no rio com sua canoa e seu remo, expressa o tempo, ou seja, do ritmo da vida dos moradores em período fora da temporada. Transmite a noção do tempo visto como sinônimo de calmaria, tranqüilidade, de um tempo social e atemporal estabelecido por relações não mercantis. Este tempo é o tempo da conversa, da brincadeira, do relacionamento com o outro, onde as práticas tradicionais são desenvolvidas e a relação com o ambiente se estreita.

\section{Discussão}

Em Itaúnas, devido às pressões externas exercidas pelas mudanças no sistema fundiário, realizadas tanto pela implantação da agroindústria, como pela Unidade de Conservação e principalmente com o desenvolvimento do turismo, o território que antes era mantido sob a lógica do comunitário, passou a se consolidar através de outra lógica, da apropriação privada e do poder.

Os moradores nativos, com o processo de expropriação de terras, consubstanciados pela sobreposição de territórios, perderam o território da floresta que utilizavam para suprir suas necessidades de subsistência para a monocultura do eucalipto e para a área de preservação. Perderam também o território da pesca que freqüentemente é invadido, em virtude da pesca industrial predatória do arrasto. De maneira simbólica, a história de "perdas" 
ainda se estende para a Vila antiga que foi soterrada e para o fenômeno da desterritorialização acentuado pelo turismo.

Em face desse contexto, percebe-se que territorialidades distintas emergem por meio dos usos empresarial, governamental e comercial. Este fenômeno vem propiciando novas formas de relação dos moradores com o ambiente que os cercam, sejam eles, o mar, as florestas, os rios, a vila etc.

O fator de destaque nessa discussão que faz emergir territorialidades inéditas em Itaúnas é a indústria do turismo. Esta se constitui em uma atividade econômica que visa o consumo da natureza e atribui outros significados as paisagens de modo diverso ao dos moradores.

Nesse sentido, são várias as formas pelas quais se produz rapidamente o novo espaço, que deverá proporcionar o descanso ou o consumo da natureza diferenciada ou, se preferirmos, das especificidades do território. Nesse processo, as amenidades de natureza mercantilizada, num primeiro momento como "pura" e isolada, passam a ser paulatinamente transformadas com a (re) produção sócio-espacial (RODRIGUES, 1996).

Desse processo decorre não só a alteração da paisagem física, como as relações sociais e as relações de trabalho dos moradores, que passam a gravitar em torno da indústria do turismo e da prestação de serviços. Todo esse processo acaba afetando a relação que os indivíduos mantêm com o território (RODRIGUES, 1996).

Em Itaúnas, percebe-se que a atividade do turismo causou forte especulação imobiliária, fato que acabou interferindo na maneira como os moradores se relacionam com o espaço que habitam. Com a valorização das casas na Vila, os moradores passaram a alugar e a vendê-las com facilidade. As casas passaram a ter outro significado para os moradores, representando "moeda viva". Quando vendidas suas casas, os moradores vão geralmente morar em locais mais afastados da área central da Vila ou coabitam na casa de parentes.

Na temporada, percebe-se também a facilidade dos moradores em se deslocarem de suas casas na intenção de alugá-las para os turistas, desenvolvendo um modo de vida itinerante. Esse fato pode ser considerado uma estratégia adaptativa que encontraram para obter dinheiro.

Constatou-se que territorialidades inéditas emergem neste cenário, ou seja, o espaço vivido passa a ser visto pelos moradores, como mercadoria, fruto das interferências geradas pelo turismo e pela especulação imobiliária, onde impera a lógica do capitalismo. 
Com o aumento do número de pessoas de fora, no período da temporada, há, muitas vezes, uma percepção de invasão do lugar, só recompensada e(ou) tolerada pelos benefícios financeiros oriundos da passagem do turista. Neste contexto, coexistem duas territorialidades antagônicas associadas respectivamente ao trabalho e ao turismo. Enquanto a praia é território de lazer e descanso para o turista, para aquele que trabalha é território de labor e cansaço (OURIQUES 2003).

O turismo também representa para os moradores, um meio alternativo de trabalho, no qual se obtém a renda. No entanto, com relação aos turistas, os moradores têm outra percepção. A cordialidade característica deles ainda se mantém, mas estabelecida atualmente sobre os parâmetros mercantis. Dessa forma, os turistas em grande fluxo, são sempre motivos de reclamação. São as contradições existentes!

Com a venda de seus imóveis, os moradores afastam-se da área mais central da Vila e passam a morar em locais mais distantes, como por exemplo, no "novo loteamento". Este se constitui numa área comprada pela Prefeitura e loteada para a venda, dando prioridade para os moradores nativos.

$\mathrm{Na}$ área central, atualmente se localizam em maior proporção os estabelecimentos comerciais como pousadas, restaurantes e bares. São os novos territórios impostos pelo turismo. Antes, esse espaço mais central era local onde residiam os moradores nativos. Hoje esses espaços são (re)apropriados pelo turismo, o que causa também uma fragmentação do território da Vila.

Ainda se referindo ao processo de deslocamento da população nativa para áreas mais afastadas, como no caso do "novo loteamento", pode-se afirmar que esse fenômeno acaba afetando as relações de parentesco, entre outras práticas e usos que são necessários para a manutenção e reprodução do modo de vida local.

Outro fenômeno que está acontecendo na Vila e que está associado a elementos da territorialidade, refere-se à venda dos novos lotes adquiridos pelos nativos que os compraram por $\mathrm{R} \$ 500,00$ (quinhentos reais) e agora os estão revendendo por $\mathrm{R} \$ 6.000,00$ (seis mil reais). Esse fato evidenciado indica que os moradores atribuem novos significados ao território, influenciados pelo turismo.

Um outro indício de territorialidade se expressa na separação que os moradores nativos estabelecem entre os nativos e pessoas de fora, chamados por eles de "forasteiros". 
Esse fato indica certo tipo de defesa do território, já que este, na visão dos moradores, em grande parte lhes foi tomado.

Mesmo com todos os aspectos negativos causados pelo turismo desenvolvido sem planejamento, pelo fato deste ser sazonal, a identidade territorial é de certa forma mantida. Pois fora de temporada os moradores voltam as suas práticas tradicionais para sobreviver. Assim, estes ainda reconhecem seu território como fonte de recursos para a subsistência, e ainda mantém os laços simbólicos e afetivos para com o território.

Por meio da análise da territorialidade, os resultados revelam que apesar das perdas sofridas dos territórios da floresta e do mar, os moradores de Itaúnas, ainda possuem conhecimento do seu território, pois ainda mantêm certa dependência para com esse, o qual ainda fornece os meios de subsistência, os meios de trabalho e a reprodução social do grupo.

Pode-se perceber que com a introdução de novas formas de apropriação do território, a população humana envolvida neste processo passa a criar novas e distintas territorialidades; ou seja, novas formas de concepção de uso e de domínio e apropriação do território, que estão ligados às suas atuais necessidades de adaptação.

Nesse sentido, acredita-se que para continuar desenvolvendo a atividade do turismo em Itaúnas, o mais prudente, mesmo diante de algumas dificuldades, é tentar buscar o turismo sustentável. Por meio do planejamento detalhado, do gerenciamento adequado de maneira estruturada e com adequada visão sistêmica, visando dessa forma diminuir as interferências negativas e potencializar os benefícios da atividade. Um dos motivos, para realizar o planejamento é a necessidade de adequação entre fluxo turístico e o núcleo receptor, o que significa atender às expectativas do primeiro sem esquecer os direitos do segundo no que se refere aos aspectos urbanísticos, ecológicos e sociais. REZENDE 2004

Segundo (Rezende, 2004) e (Ignarra, 2000), para desenvolver a atividade do turismo dentro da proposta de um turismo ecológico e socialmente justo, existem definições e recomendações que orientam as políticas de implantação dessa modalidade. De acordo com as autoras o ecoturismo é uma modalidade de turismo que visa à preservação do meio e o bemestar da população local.

Definido pela OMT (2003), o ecoturismo constitui-se numa forma de turismo baseada na natureza, com grande ênfase na conservação do meio ambiente, incluindo a diversidade biológica, os sistemas de vida selvagem e ecológico, ressaltando a importância da educação do turista quanto ao ambiente ao modo de conservá-lo. As áreas de ecoturismo incluem 
comunidades humanas, especialmente de povos tradicionais dessa forma, o plano de ecoturismo precisa estudar as maneiras de conservar as tradições e as identidades locais e o modo de levar benefícios a estas comunidades.

Entre as sugestões da OMT (2003), para o planejamento do ecoturismo estão, estabelecimentos de padrões de capacidade de carga; medidas rigorosas de conservação da área natural; desenvolvimento de um centro de recepção ao visitante, com exposição sobre o local e sobre as técnicas de conservação; disponibilizar guias bem treinados, que possam oferecer informações exatas aos turistas; integrar as comunidades locais a atividade turística melhorando as condições de vida dessas.

Pensando na sustentabilidade de Itaúnas, o mais correto, seria desenvolver o ecoturismo em Itaúnas tomando-se como base: a valorização das características culturais da região como o Ticumbi, Jongo, pesca artesanal, a casa de farinha; a criação de um núcleo direcionado ao planejamento do turismo; estímulo ao desenvolvimento de pesquisas que tratem da questão do turismo; uso sustentado dos recursos; formas alternativas de renda e sobrevivência para a população local e a necessidade da participação democrática na gestão territorial.

\section{Considerações finais}

Os resultados obtidos nessa pesquisa, interpretados por meio do conceito de territorialidade, apontam que processos de sobreposição no uso do território, causam uma fragmentação do mesmo. Nesse contexto, a lógica de apropriação do território é quase sempre alterada. No caso de Itaúnas, essa vem deixando de ser comunal para atender a diversos interesses, tanto de preservação como de uso e exploração, causando alguns conflitos de ordem ecológica, social, cultural e econômica. Constatou-se que a sobreposição no uso do território (geográfico, simbólico, afetivo etc.), em virtude do desenvolvimento do turismo sem planejamento, vem gerando a desterritorialização, fenômeno responsável por diluir as identidades territoriais.

No novo cenário imposto, com a ausência de espaço para obtenção de recursos necessários à sua sobrevivência, a população humana vê-se forçada a adicionar novas atividades de subsistência às antigas práticas culturais. Assim, como estratégia adaptativa, vem buscando inserir-se em novas atividades econômicas, principalmente aquelas ligadas ao turismo. 
Observou-se, em Itaúnas, a coexistência de territorialidades distintas que se concretizam por meio de usos diversos: comunais tradicionais, empresariais, comerciais e governamentais. Com isso, a população local, passa a criar e a incorporar novas concepções de uso, domínio e apropriação do território.

Este estudo ainda revela as situações de vida da comunidade estudada, atentando para a cultura e tradição locais e o manejo dos recursos naturais locais, com o objetivo de contribuir para caracterizar tal interação e estabelecer perspectivas para planos de conservação do ambiente em que estão inseridos.

\section{Referências}

ANDRADE, M. Territorialidades, desterritorialidades, novas territorialidades: os limites do poder nacional e do poder local. In: SANTOS, M.; SILVEIRA, M.A. (Org.). Território, globalização e fragmentação. 5.ed. São Paulo: Editora Hucitec, 2002. p.213-220.

CHAVEZ, M.G.G. Biodiversidade e conhecimento local: do discurso à prática baseada no território. In: ENCONTRO NACIONAL DE PÓS-GRADUAÇÃO E PESQUISA EM AMBIENTE E SOCIEDADE. 1., Campinas, 2002. http:// www.scielo.org (28 nov. 2003).

CARLOS. A. F A. A cidade. São Paulo: Contexto, 1999.

FARIA, I.F. Hotéis de selva e novas territorialidades no Amazonas. In: FARIA, I.F. Turismo: sustentabilidade e novas territorialidades. Manaus: Editora da Universidade do Amazonas, 2001. p.115-127.

FERREIRA, S.R.B. Da fartura à escassez: a agroindústria de celulose e o fim dos territórios comunais no extremo norte do Espírito Santo. São Paulo, 2002. 204p. Dissertação (Mestrado) - Faculdade de Filosofia, Letras e Ciências Humanas, Universidade de São Paulo.

GIARETTA, M. J. Turismo da juventude. São Paulo, 2002. 119p. Tese (Doutorado) - Escola de Comunicação e Artes, Universidade de São Paulo.

GIL, A.C. Métodos e técnicas de pesquisa social. 5.ed. São Paulo: Atlas, 1999. 206p.

GOVERNO DO ESTADO DO ESPIRITO SANTO DO ESPIRITO SANTO. Fundamentos para a elaboração do plano de ordenamento da Vila de Itaúnas-ES. Vitória, 2001. (Relatório Preliminar).

HAESBAERT. R. Territórios alternativos. Niterói: Editora UFF; São Paulo: Contexto, 2002. 173p.

IGNARRA, L.R. Fundamentos do turismo. 2.ed. São Paulo: Pioneira Thomson Learning, 2000. 135p.

LITTLE. P.E. Territórios sociais e povos tradicionais no Brasil: por uma antropologia da territorialidade. Série Antropologia n.322, Brasília, 2002. http// www. unb/ics/dar/serie322empdf.pdf (09 set. 2004).

OURIQUES, H.R. Território e Turismo: uma reflexão inicial. Revista eletrônica de turismo. Abril, 2003. In:http://www.revistaturismo.com.br/artigos/territorioturismo.html

PETROFF, M.A.D.S. Levantamento dos rapinantes do Parque Estadual de Itaúnas e os impactos das atividades sócio-econômicas. São Paulo, 2003. 78p. Dissertação (Mestrado) Instituto de Psicologia, Universidade de São Paulo.

POSEY, D. A. Etnobiologia: teoria e prática. Summa Etnológica Brasileira Petrópolis, RJ. FINEP. Vol.1 (Etnobiologia): 15-28. 1986. 
RAFFESTIN, C. Por uma geografia do poder. Trad. de M.C. França. São Paulo: Editora Ática, 1993. 226p.

REZENDE, C.F. Ecoturismo como instrumento de desenvolvimento: limites, desafios e potencialidades. Lavras, 2004. 115p. Dissertação (Mestrado) - Universidade Federal de Lavras.

RODRIGUES, A.M. A produção e o consumo do espaço para o turismo e a problemática ambiental. In: YAZIGI, E. Turismo-espaço, paisagem e cultura. São Paulo: Hucitec, 1996. p. 55-62.

SANTOS, M. Por uma outra globalização. São Paulo: Record, 2002.

SANTOS, C. Ensaio sem Referências Aparentes ou Em Busca de uma Ecoexossomia. Primeira versão. Ano I no 111. Setembro. Porto Velho, 2002.

WILSON. E.O. Da natureza humana. São Paulo: EDUSP e Editora T. A. Queiroz, 1981. 263p. 